stalked papilloma growing from the healed scar of a tracheotomy wound and causing obstruction of the larynx.

With the exception of the effect on tracheotomy cases, it is impossible to draw from the above statistics any strong evidence in favour of the serum treatment; nevertheless, noting the decided improvement in the statistics of the later years, the increased success of tracheotomy, the rapid clearing of the throat after injection, and the many details not capable of being reduced to statistics, there seems no doubt that the antitoxic serum has been of great value in the treatment of diphtheria. With a greater uniformity in the strength of the serum supplied, and a more accurate knowledge of the dosage, a better result may be hoped for.

\section{NOTES ON \\ TWO CASES OF TOXIC AMBLYOPIA FROM IODOFORM.}

By JAMES W. RUSSELL, M.A., M.D. Cantab., M.R.C.P. LoND.,

ASSISTANT PHYSICIAN TO THE BIRMINGHAM GENERAL HOSPITAL.

During the last two years I have treated most of $\mathrm{my}$ phthisical out-patients with considerable doses of iodoform, according to the system advocated by Dr. Foxwell in a paper published in the Birmingham Medical Revien in August, 1894. As to the real value of the treatment I hope shortly to obtain some evidence by the analysis of my cases, and I may here merely say that I have hitherto firmly believed that comparatively good results are to be obtained by its means. The dose taken has varied with the circumstances of the case. Generally, unless any special contra-indication has been observed, the initial dose has been two grains three times a day, and this has been increased by two grains per dose every week, as inquiry showed the absence of toxic symptoms. From eight to ten grains has always been the maximum dose, and when this quantity has been reached constant inquiry for symptoms of poisoning has been made, and occasional intermissions in the treatment have been insisted upon. In only two cases have I observed any important symptoms of poisoning from the use of the drug, and in each of these the symptom has taken the form of a well-marked amblyopia. The following are brief notes of these cases, for part of which I am indebted to Dr. Wood White, who kindly examined the patients at the Birmingham and Midland Ege Hospital at my request.

CASE 1.-The patient, a man aged thirty-two years, came to my out-patient department on March 26th, 1896, complaining of cough, wasting, and shortness of breath of recent onset. On examination, signs of early phthisis were found at the apex of each lung. He was ordered a mixture containing cod-liver oil and iron and two-grain pills of iodoform to be taken three times a day. On April 16th he had been taking six grains three times a day for a week, and complained of a disagreeable "metallic" taste and smell ; I therefore reduced the dose to four grains, and nex week he reported that these symptoms had practically ceased. On May 7 th the dose was increased to five grains, and from this time the quantity taken was gradually in creased, without any further complaint on the part of the patient, until on June 18 th ten grains were ordered to be taken three times a day. On July 9 th an inquiry as to the condition of the sight elicited the fact that for the last $w 0 \mathrm{k}$ or two he had experienced some increasing difficulty in reading, especially at night; the iodoform was accordingly * opped and the patient was sent to the Birmingham and Nidland Eye Hospital for examination. On July 20th Dr Wood White reported that the vision of each eye was reduced to $\frac{8}{18}$. Beyond the omission of the iodoform no special treatment of the condition was adopted, but on Aug. 6th Dr. Wood White reported that the vision of each eye was $\frac{6}{5}$ and on Nov. 26th it was noted that the sight was normal.

CASE 2.- The patient, a man aged twenty-six years, first attended my out-patient department on Sept. 14th, 1895, complaining of an attack of bæmoptysis which had occurred a few days previonsly. He had been suffering of late from profuse night sweats; there were, however, no definite physical signs to be found in the lungs. During the next six weeks he had several further attacks of hæmoptysis, and by the end of October had developed distinct signs of phthisis at the left apex. On Sept. 28 th he was ordered to take one grain of iodoform three times a day, together with a mixture containing cod-liver oil and iron. The quantity of iodoform was slowly increased, and on Nov. 2nd had reached eight grains per dose; and although I find that for some reason the dose was on Feb. 1st, 1896, reduced to six grains, yet on April 26th he was again taking eight grains, his weight having increased by eight pounds since the beginning of treatment. Shortly afterwards the dose was increased to ten grains. From this time he continued, with occasional intermissions, often of a few weeks' duration, to take varying quantities of iodoform, with apparently excellent results ; but on Jan. 2nd, 1897, after having taken ten grains of iodoform for only three weeks continuously, he stated in answer to my inquiry that he had noticed of late some increasing difficulty in reading, again especially at night. The iodoform was at once stopped, and $\mathrm{Dr}$. Wood White, who examined the patient at the Birmingham and Midland Eye Hospital, kindly sent me the following report of his condition: "Consensual light and accommodative reflexes present. There is no reflex on stimulation of sensory nerves in either eye. Vision: right eye, $\frac{5}{20}$, improved by +50 cylinders; left eye, $\frac{5}{2^{5}}$ colour vision normal; right field of vision normal; left slightly contracted; discs pale, but not atrophied. The amblyopia in this case differs from that due to tobacco in that there is no central colour scotoma" After the above examination the patient failed to attend at either hospital for some time, but returned to my out-patient department early in April. He stated that his sight had rapidly recovered after leaving off the iodoform; and on testing I found that it was normal in each eye. His chest was free from signs of active mischief, and he looked and felt in good health.

The cases of toxic amblyopia from the administration of iodoform hitherto published are few in number. In a paper describing one such case, published in 1893 in the Opllthalmic Review by Mr. Priestley Smith, reference is made to two cases as the only ones then recorded. One of these was published by Hirschberg in $1882,{ }^{1}$ and resulted from the local application of iodoform ; the other, recorded by Dr. $\mathrm{E}$. Hutchinson, ${ }^{2}$ was due to its internal administration. The third case, published by Mr. Priestley Smith, occurred in the out-patient practice of Dr. Foxwell at the Queen's Hospital, Birmingham, and was also caused by the use of the drug internally in considerable doses. I have been unable to discover any later addition to the literature of the subject. It is difficult to say in what proportion of cases treated with iodoform amblyopia is likely to make its appearance. Dr. Foxwell seems to regard the symptom as a very uncommon one; my cases would rather suggest, however, that when large doses are taken for any length of time it is likely to be not very infrequently met with. On referring to my case-books I find that I have notes of 187 cases in which iodoform was administered, excluding all those in which the patient attended a single time only. Of these 187 patients 20 complained of the unpleasant taste and smell to which the drug is apt to give rise; and 12 of these were taking only six grains or less at the time. Of the two patients who suffered from amblyopia only one had complained of the taste of the pills. It is to be noted, however, that in only a certain proportion of the cases did the dose reach as much as eight or ten grains ; and that, moreover, a considerable number of the patients attended for but a short time only. The following table will present a summary of these points :-

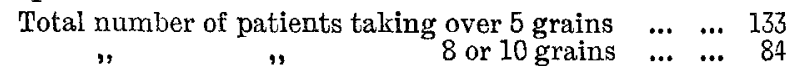
Attended "over 6 month." ... 4 ...... Maximum dose 10 grains 4 from 3 to 6 months 12 ....... from 6 weeks to

3 months

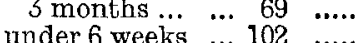

Again, the time during which the large dose has been taken has varied considerably, 27 patients taking this dose for periods varying from four weeks to five months, with occasional intermissions, as already described. None of these patients developed any important signs of poisoning during the continuance of the large doses, but $5 \mathrm{com}-$ plained of the smell or taste at some period of the treatment. The 2 patients who developed amblyopia had each

1 Centralblatt fur Praktische Augenheilkunde, p. 92.

2 New York Medical Journal, Jan. 2nd, 1886. 
been taking ten-grain doses for three weeks only at the time when the symptom was reported.

Since the cases above referred to, together with the two recorded in this paper, appear to establish the fact that iodoform is liable to cause amblyopia, it becomes a question whether its use internally is any longer justifiable. This question may, I think, be answered in the affirmative, always supposing that the treatment is of real value. In my own cases and in that recorded by Hirschberg, recovery was complete and rapid after the discontinuance of the iodoform; in the other two recovery was progressing satisfactorily when the last notes were taken. It therefore seems probable that if the amblyopia be early recognised and the drug promptly omitted no permanent mischief need be feared. I have now adopted the plan of recording the vision of all those patients whom I am about to treat with iodoform before beginning its administration; I then make periodical inquiries as to the sight, and am able to discover when any diminution is acknowledged whether alteration has really taken place. This measure is, I find, absolutely necessary owing to the certainty in hospital out-patient practice that any symptom frequently inquired for will sooner or later be acknowledged by the patient. I have only to add that in my cases the onset of the amblyopia was not accompanied by any other symptom.

Birmingham.

\section{FOUR SUCCESSFUL CASES OF TRANS- FUSION OF SALINE FLUID.}

By NATHAN RAW, M.D. DURH., \&C.,

MEDICAL SUPERINTENDENT AND PATHOLOGIST, DUNDEE ROYAT. INEIRMARY.

In The LANCeT of Aug. 17th, 1895, I recorded six successful cases of transfusion of normal saline solution, and since that time several cases have occurred in the practice of whe Dundee Royal Infirmary in which transfusion has been employed, in some with wonderful effect and in others with well-marked temporary improvement. The following is a brief note of the successful cases.

CASE 1.-A woman, aged thirty-nine years, pashed her arm through a window, severely lacerating it. She bled profusely and on admission to the infirmary an hour afterwards was in a very serious condition. She was quite unconscious and markedly anæmic; the respiration was shallow, with occasional sighing; no pulse could be -detected. She had a transverse wound over the front of the left elbow-joint severing the radial artery at its origin. The median cepbalic vein was also divided, and into this were transfused five pints of normal saline solution at a temperature of $105^{\circ} \mathrm{F}$. The effect was very wonderful. In a few minutes she opened her eyes, consciousness slowly returned, and the pulse became quite good and regular. She made a good recovery and went home in ten days.

CASE 2.-A boy, aged twelve years, was admitied to the infirmary on March 25th, 1896, under the care of Dr. MacE wan, with extensive disease of the right knee-joint. He was in a fairly healthy condition. Dr. MacE wan excised the right knee-joint, and numerous tuberculous deposits were found in the femur and tibia, even above the epiphyseal lines. The medullary cavity of the femur was opened and drained. The patient did not suffer from shock or loss of blood, and he bore the operation well. He remained fairly well for thirtysix hours, when he suddenly developed a rigor and became delirious; his temperature was $103^{\circ} \mathrm{F}$. and his pulse 144 . The wound was dressed but found to be sweet. Eight hours afterwards he was quite unconscious and apparently dying. The left internal saphenous vein was opened, and four pints of saline fluid were introduced with a very good effect, as, with the exception of a severe rigor half an hour after the injection, he made a good recovery and is now almost well.

CASE 3.-A man, aged thirty-two years, had his arm caught in machinery, rupturing the brachial artery and smashing the arm. He lost a very large amount of blood and when brought to the hospital was in a very collapsed state. Amputation at the shoulder-joint was performed. He suffered from collapse, and during the night his pulse could not be felt. He was transfused with five pints of saline fluid. An hour afterwards he had a rigor, with a temperature of $103^{\circ} \mathrm{F}$, but with this exception he made a rapid recovery.

CASE 4 -A woman, aged twenty-three years, was admitted on June 6th, 1896, under the care of Dr. Whyte, suffering from purpura and anæmia. She had several severe attacks of violent epistaxis which were difficult to control. The patient's condition became very serious; the pulse was quite imperceptible, and she was apparently dying. She was transfused with five pints of saline solution, with the effect noticed in Cases 2 and $5-v i z .$, a rigor and temperature of $104^{\circ} \mathrm{F}$. one hour later. She revived almost at once and made an excellent recovery.

Remarks.--There can be no doubt that we have in transfusion one of the most simple yet efficacious remedies in all cases of shock from hæmorrhage. How far it is of service in cases of nervous shock and collapse is yet undecided, but in some cases it is of great value. Larger quantities should be given than those generally recommended, four or five pints being a usual quantity. I have given as much as twenty-four pints at four injections within twenty-four hours without any apparent discomfort. I have noticed in several cases the occurrence of a rigor, commencing from half an hour to an hour after the operation and lasting about five minutes, with a high temperature. This seems to have no serious effect, the temperature quickly subsides, and recovery is not retarded by it. In Case 2 there is every reason to suppose that an acute attack of septic osteo-myelitis was cut short by the transfusion, my explanation being that an increased volume in the vessels would offer a greater resistance to attack and at the same time dilute the blood stream and so disperse the micro-organisms. If this be so, there is reason to suppose that transfusion may be employed in acute specific diseases due to micro-organisms, as in any case it could have no other than a highly beneficial effect if performed with ordinary care and with a sterilised solution. The apparatus I use consists of an ordinary glass funnel and tubing, with a glass nozzle for insertion into the vein.

Dundee.

\section{NOTES ON THE ANATOMY, DEVELOPMENT, PATHOLOGY, AND SURGERY OF THE FRONTAI SINUSES.}

By MAYO COLLIER, M. S. LOND., F.R.C.S. ENG., SENIOR ASSISTANT SURGEON TO THR NORTH-WEST LONDON HOSPITAX.

Anatomy.-The frontal sinuses are generally two irregular cavities between the inner and outer tables of the frontal bone, near the root of the nose. In the fresh state these cavities are lined with a thin, pale, closely-adherent mucous membrane, and separated from each other by a well-marked septum. They usually communicate separately with the corresponding nasal cavity by an opening, variable in size, leading into the anterior extremity of the middle meatus of the nose. The examination of a large number of frontal sinuses in the moist and dry state discloses many points of interest. In the first place there is no space between the tables of the frontal bone before the seventh year. There may be a complete absence of these cavities even in extreme old age. I have bones in my possession showing a frontal sinus only on one side. The extent of the frontal sinuses varies widely, and unfortunately the external appearances of the skull give no indication of these variations. The frontal sinuses are seldom symmetrical, except in a general sense. Of the extent of these spices there are specimens in the Museum of the Royal College of Surgeons of England, showing a separation of the inner and outer tables of the frontal bone almost to the coronal suture. The orbital plate of the frontal bone is frequently the site of a large cavity communicating with, and forming part of, the frontal sinuses. The frontal sinus of one side may not communicate with the nose or its fellow of the opposite side, but may communicate with the anterior ethmoidal cells of the same side. The septum dividing the two sinuses is usually partly bony and partly fibrous, but is always well marked. It may be entirely bony or entirely fibrous. Its central position is constant. I have never found a frontal sinus not in communication, directly or indirectly, with the nose. The evolution of the frontal sinuses is not complete until the twenty-first year. 